\title{
Reseña
}

\section{Bergua Amores, J. A. (2015): Postpolítica. Elogio del gentío, Madrid, Biblioteca Nueva. 256 págs.}

Postpolítica es un libro único en algunos aspectos del cual podríamos afirmar que reside en las fronteras de la academia. De hecho, sólo la primera parte de las dos que componen el libro puede entenderse utilizando el modo de pensar característico de las universidades contemporáneas. Cuando llegamos a la mitad del texto, en cambio, y aquí debemos cruzar una frontera titulada "Intermezzo", nos encontramos con un discurso fundamentado por fuera de los conceptos habituales en las Ciencias Sociales. Esto último, sin embargo, no implica que el libro deba ser ignorado por las academias; más bien lo contrario, su singularidad lo hace imprescindible porque nos obliga a pensar desde otra perspectiva. Dicho esto a pesar de que el autor, Doctor en Sociología (UCM) y profesor en la Universidad de Zaragoza con acreditación de Catedrático, encuentra antecedentes de pensadores, incluso clásicos, que en ocasiones recurrieron a figuras esotéricas para fundamentar argumentos y sostener teorías.

El título del libro remite a un escenario de abandono o superación de la política, definida ésta como "un subconjunto de lo social" (p.13). La idea de una sociedad futura sin política (ni Estado), al menos en el sentido formal del concepto, ya estaba presente en el marxismo y el anarquismo. Del primero Bergua dirá que su discurso se ha vuelto en gran parte inútil y que tiene "...concepciones finitas y austeras de lo natural y lo social así como modos muy cerrados, estables y simples de interpretar la articulación de los distintos componentes del bios y del socius" (p. 166); el segundo inspira desde el título a su libro anterior (2013) y, aunque distinta del anarquismo clásico, la anarquía es una idea central en el autor. Desde esta perspectiva, buscando modos autónomos y horizontales de lo social, Bergua se ubica en posición de lucha frente a una realidad instituida (hecha de códigos, reglas e instituciones) que, por otra parte, encuentra en estado decadente; al punto que la propia Democracia "se está desmoronando" (p. 15).

De la Democracia sólo puede rescatarse su fundamento, es decir, el demos, al cual Bergua denomina indistintamente como "gente", "comunidad" o "multitud". Únicamente queda asirnos a las ideas, afectos y pasiones de la gente, entorpecidas hoy en día por instituciones, normas y regulaciones que no están a la altura de las circunstancias y, por lo tanto, deben ser destituidas. Piénsese aquí en el subtítulo del libro: "Elogio del gentío". Bergua reconoce este gentío inspirador en los llamados "indignados" que se movilizaron el 15 de mayo de 2011 en España. Los indignados personificarían al plano esotérico (régimen nocturno de la Política), el cual está, a su vez, asociado con lo sagrado que vincula a las gentes, es decir, lo "... pre-humano e in-humano que precede, atraviesa, rodea y excede lo social” (p. 18). Además del antes 
citado, Bergua reconoce al plano exotérico (régimen diurno de la Política, expuesto en la primera parte), inspirándose aquí en Giles Durand (1984). Las movilizaciones populares en el marco de la crisis española evidenciarían una falla irreparable en las agencias del régimen diurno de la Política que dejó un vacío sólo posible de recomponer a través de la sabiduría del gentío religado. Allí donde el plano exotérico ha fracasado, el esotérico funciona como una reserva de energía disponible en las propias gentes para las cuales, por otra parte, se piensan, gestionan y ejecutan las políticas a través de la llamada administración y gestión pública, tecnocracia incapaz de vehiculizar el potencial del gentío.

Bergua se asume postdemocrático, rechaza la lógica de la representación y entiende, de hecho, que la Democracia conforma una contradicción en su nombre, aquella entre el demos y el kratos. La inconmensurabilidad del primero excederá siempre al segundo; el demos desborda y desequilibra al kratos. En definitiva, la Democracia jamás estará a la altura del gentío porque solamente las gentes pueden multiplicar su entorno con su desmesurada creatividad y concebir un mundo social plural y autónomo. Debemos plantear un horizonte de acracia con la consecuente supresión de las jerarquías y la autoridad en que éstas se envisten, porque el demos puede autorregularse sin normas, instituciones y disposiciones que lo suplanten, conduzcan e interpreten (p. 112).

Bergua, recurriendo a Dupuy (1991), nos explica dos tipos de sociabilidades que implican, a su vez, dos modos de observar la realidad: el paradigma del punto fijo exógeno (estable) y el del endógeno (metaestable). Si el primero es propio del Estado (y sus élites), el segundo lo es del gentío. En suma, el gentío se organiza en anarquía de una manera tal que lo social acontece en términos endógenos y emergentistas, sustituyendo a los puntos reguladores exógenos. El Estado, gran punto regulador exógeno, es prescindible y extinguiéndolo quedará en su lugar la autonomía anárquica del demos. Si la gente es un torbellino vital inaprensible, el Estado es un dique que intenta detener y contener a esa fuente tumultuosa y desbordante. El Estado es, pues, una excrecencia que pretende dominar por completo lo social con la ayuda de élites normalizadoras (p.45), marchitando la singularidad de las gentes. Las élites no pueden aprehender la sabiduría del gentío, son ignorantes e incompetentes, no saben que no saben e intentan equilibrar el potencial de lo social a través de un atractor estable y fijo (el Estado), cuando lo sagrado (o social) es impredecible y su acontecer está lejos de tender a un equilibrio deseado. Los órdenes e instituciones contemporáneas traicionan a la creatividad del gentío. Además, las élites han olvidado que todos los órdenes instituidos sólo existen por la potencia instituyente de las gentes.

Cuando en la segunda parte el saber académico le da lugar al ocultismo, la magia y el chamanismo, es decir, al saber esotérico, sentimos que Platón debe marcharse para que regrese la sabiduría presocrática; aquello que fue antes de la Academia y su fundación racionalista, meticulosa, dispuesta a mensurar al conocimiento. Por el camino del logos Platón concibe una sociedad cerrada, estamental, regulada por uno o pocos sabios filósofos; Bergua propone desbordar al logos yendo desde lo definido y finito hacia lo transfinito (p.18) y sus ideas aspiran a una comunidad abierta, anárquica, donde el potencial instituyente del demos regule y gestione aquello que proviene del vínculo entre el socius y el bios, el cual reposa en lo sagrado. El gentío tiene la capacidad 
de prescindir de intermediarios para construir y comprender por sí mismo lo social ( $\mathrm{p}$. 24), por lo cual las élites científicas, periodísticas y políticas de los órdenes instituidos actualmente tampoco son necesarias si lo que buscamos es un mundo social autónomo.

Siempre que pensamos una sociedad sin Estado tememos lo mismo que antaño Hobbes: una muerte violenta. Incluso los neoliberales, excepto el anarcocapitalismo, aceptan la necesidad del Estado, al menos mínimo, para velar por la seguridad de los ciudadanos. En suma, podríamos cuestionarnos el problema de la violencia en tanto no haya una institución que reclame con éxito su monopolio legítimo, ni un tercero imparcial que resuelva los litigios entre partes. El autor nos responderá que el gentío puede lidiar con la violencia sin necesidad de un punto fijo exógeno que la estabilice y controle. Si el Estado propuso sin éxito extirpar la violencia y muchas veces recayó en la versión más destructiva, el demos se ubica en un punto intermedio, aceptando la posibilidad de conflicto y disputa; el demos, “...como el caos determinista y los órdenes por fluctuaciones, se ubica entre el exagerado orden del Estado y el azar más absoluto..." (p. 93). Aquí entra en juego el principio de reciprocidad como una manera de contratar socialmente para crear la paz (no perpetua) y sublimar (desactivar) la violencia. Debemos reconocer que en los regímenes totalitarios allí donde el Estado se hizo más fuerte y adquirió el control total por sobre las gentes, fue precisamente cuando la violencia estatal se convirtió en terror y exterminó al tejido social. Claro que a Bergua le resulta insuficiente el llamado Estado de derecho porque en los estados liberales de cualquier índole seguiríamos dentro de arquías.

El autor nos advierte que en la segunda parte del libro debemos pensar desde nuestro lado oscuro. El régimen nocturno de la Política prescinde de científicos y políticos por considerarlos inútiles, en tanto entienden solamente de jerarquías y estabilidad, recurriendo en su lugar a los brujos, chamanes y magos, maestros del ocultismo que, como mediadores, pueden comunicar con otros mundos y religar a las gentes con lo sagrado primordial. Será desde este acontecer daimónico desde donde la gente ejerza su soberanía, yéndonos de la Democracia a la demopoiesis; aquí ya no es el individuo, sino la desmesura la única agencia a tener en cuenta (p.166). Estamos en un escenario donde la "comunión" del gentío es gozosa porque se activan y emergen los vínculos más profundos asociados al querer estar juntos y vivir con los otros; se activa también la creatividad propia de las gentes. Sin el demos, el kratos o política es nada. Y la política contemporánea redujo la participación popular al mínimo, dejando el poder en mano de instituciones intermediarias las cuales, a su vez, dentro de sí mismas concentran el mando en una oligarquía elitista.

Bergua advierte que desde tiempos remotos el demos ha sido mencionado como fundamento, pero todos los órdenes instituidos hasta la actualidad de un modo u otro lo han traicionado, ningún cuerpo político fue capaz de dar cuenta de la heterogeneidad creativa del gentío. Hoy existen, sin embargo, hombres que recuerdan tiempos inmemoriales a partir de la anamnesis, haciendo uso de un ultraconsciente pre-societal; así superan al ego subjetivo y al kratos impuesto en lo social y van en camino a un mundo igualitario. Habría, pues, un cambio de clima para la construcción de una nueva soberanía de las gentes. Siguiendo a Wilber (1989), Bergua cree percibir esta nueva atmósfera en el hecho de que cada vez más gente tiene experiencias transpersonales de 
tipo creativo o centáurico (p. 144). Serán los sujetos centauros quienes permitan arribar a lo nuevo que está por nacer, donde se transciendan el ego y las jerarquías, pues su creatividad hará emerger nuevos sentidos desde lo ordinario. En tanto ocultistas serán magos, brujos y chamanes que pondrán todo en relación y devendrán canales para que los sujetos se disuelvan en la interioridad del socius. Siguiendo este camino la Sociosofía trascenderá a la Sociología y el analogismo será la ontología que alumbre otro mundo posible (p.88). Como se intuye, la propuesta de Postpolítica, aunque por momentos nos recuerde a otros autores, por ejemplo a Georges Bataille y su búsqueda de una sociología sagrada, implica un cambio radical en el análisis de lo social.

Postpolítica conmueve de un modo extraño. Bergua confiesa que corre el riesgo de no agradarle a nadie porque ha escrito un libro molesto tanto para científicos como para poetas. Si bien hay erudición académica en sus páginas y el mismo autor le da valor al conocimiento racional, en algún punto el texto exige cierto apasionamiento, cierta profesión de fe. Una fe con una buena nueva muy distinta a aquella que anunciaron las religiones monoteístas. Bergua proclama un objetivo desafiante: “...queda pendiente la (re) conquista de lo sagrado" (p. 141). Veremos cuál será la fortuna de este desafío y de su interesante trabajo. Por lo pronto estamos frente a un libro disruptivo, poco amable para la academia actual y, aunque desconocemos si también será singular para las academias del futuro, hoy más bien puede que tenga el destino que Bergua le asigna a la Sociosofía que, como todo saber esotérico, debe permanecer oculto, no debe ser divulgado y enseñado como la Ciencia (p.175). Tal vez este libro anuncie una sabiduría por venir; pero sobre este nuevo paradigma nosotros, los académicos, aún lo ignoramos todo.

\author{
Matías Morales Beascoechea \\ $\mathrm{UBA} / \mathrm{UNLaM}$ \\ matiaslmorales@hotmail.com
}

\title{
Bibliografía
}

Bergua Amores, J. A. (2013): Anarquías, ámbitos no jerárquicos de lo social, Buenos Aires, Lumen.

Dupuy, J. P. (1991): La panique, Paris, Laboratoires Delagrange.

Durand, G. (1984): Les estructures antropologiques de l'imaginaire, Paris, Dunöd.

Wilber, K. (1989): El proyecto Atman, Barcelona, Kairos. 